Submission ID: 43968

\title{
Generation Potential and the Coverage Area of Domanik Formation in the Northern Part of the Timan-Pechora Province Based on Geochemical Studies and Depositional Modelling
}

\author{
O. Bogoyavlenskaya* (LLC RN-Shelf-Arctic), G. Ulyanov (LLC RN-Shelf-Arctic)
}

\section{SUMMARY}

\begin{abstract}
The purpose of the work is to determine the position of the carbonate zone and the location of the source rocks in the upper Paleozoic section at the transit zone between offshore and onshore parts of the TimanPechora oil and gas province. This research is based on the modeling of processes of formation of the domanik-tournaisian carbonate complex. The work was done for the purpose of clarification and verification of paleogeographic models and forecast of oil and gas potential of the study area.

Regarding to the previous paleo-reconstruction study and results of seismic interpretation the reef system may have submeridional and sublatitudinal orientations.

According to results of the modeling the most reasonable system of domanik-syracusecoe barrier reef is sublatitudinal. Which turned out to be the most consistent on most parameters.

The resulting sediment zonation allowed us to localize the zone of distribution of the reefs. In frontreef area within synclines were determined several positive structures with different relief. The arches of these structures might represent different types of single reefs.

The result of this study shows different deposition type in the Pomorskiy val area. The deposits are representing the single reef in backreef zone, but according to the earlier study it was determined as continuation of the barrier reef.

As a result, the paleo-facies map for the frasnian age was corrected and detailed.
\end{abstract}


Прогноз генерационного потенциала и областей распространения доманиковых отложений северной части Тимано-Печорской провинции на основе геохимических исследований и седиментационного моделирования.

О.В. Богоявленская* (ООО «РН-Шельф-Арктика»), Г.В. Ульянов (ООО «РН-Шельф-Арктика»)

\section{Введение}

Доманиково-турнейский комплекс Тимано-Печорской провинции является уникальным как по сложности и многообразию геологических объектов, так и по условию их образования. Формирование отложений происходило в различных обстановках осадконакопления: от прибрежных (приливно-отливных и мелководно-шельфовых) на западе до умеренноглубоководно-шельфовых на востоке.

Целью работы являлись уточнение и верификация палеогеографических моделей северной части Тимано-Печорской провинции, с применением методики седиментационного моделирования процессов формирования карбонатного комплекса доманиково-турнейского возраста. Построение седиментационной модели было выполнено в программном обеспечении (ПО) DionisosFlow (BeicipFL).

Для прогноза областей распространения, литологического состава и потенциала НГМТ доманиковой формации в комплексе с седиментационным моделированием был проведен анализ результатов геохимических исследований образцов из скважин акватории Печорского моря и прилегающей суши.

\section{Методика}

Масштабы карбонатного осадконакопления контролируются множеством факторов освещённостью, температурой воды, соленостью, содержанием и поступлением питательных веществ и др., которые в свою очередь определяются 3-мя глобальными условиями: тектоникой, изменением относительного уровня моря (ОУМ) и климатом. Эти условия учитываются при построении моделей карбонатного осадконакопления в используемом ПО (рис.1).
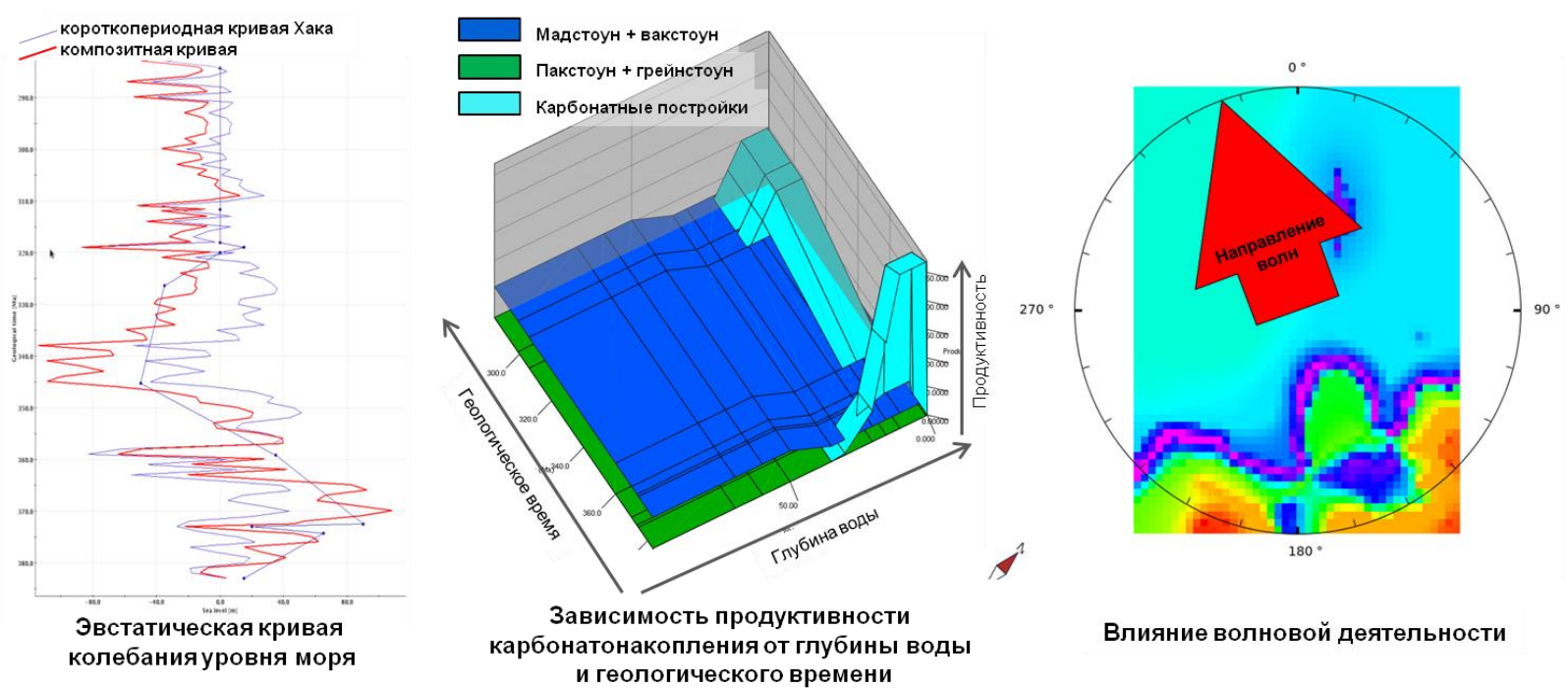

Рисунок 1 Ключевые исходные параметры модели.

Моделирование процессов формирования карбонатного интервала разреза проводилось с использованием данных региональной геологии, тектоники и стратиграфии по акватории 
Печорского моря и прилегающей к ней суше. В качестве априорной модели карбонатонакопления рассматриваемого региона были приняты наиболее обоснованные построения разных авторов [1 - 3]. В качестве основной была принята модель В.А. Жемчуговой, с учетом новых данных, полученных специалистами ООО «РН-ШельфАрктика» при детализации сейсмостратиграфической и сейсмофациальной моделей региона.

\section{Моделирование}

В осадочном чехле Тимано-Печороморской провинции, включая ее акваториальное продолжение, важную играют карбонатные породы, слагающие разрез нижнего и верхнего девона, карбона и нижней перми.

Начало позднего девона (D3) характеризуется развитием региональной трансгрессии и началом образования относительно глубоководной окраинно-шельфовой впадины. На бровке мелководного шельфа на этапах повышения ОУМ создавались благоприятные условия для формирования рифовых систем преимущественно барьерного типа. На отмелях в пределах умеренно-глубоководно-шельфовой области также периодически существовали благоприятные условия для формирования одиночных рифогенных построек и их групп. За рифовыми системами во время их развития происходило накопление преимущественно карбонатных мелководно-шельфовых осадков и реже, при значительной изолированности - лагунных образований. В умеренно-глубоководно-шельфовой области одновременно с развитием рифовых систем формировались относительно глубоководные глинисто-карбонатные отложения доманиковой формации. При понижениях ОУМ область умеренно-глубоководного шельфа последовательно компенсировалась перекрывающими толщами заполнения (отложения проградирующих террас).

В течение средне- и позднефранского, фаменского и турнейского времени эта впадина мигрировала в сторону Палеоуральского океана, и постепенно заполнялась осадками вследствие преобладающей регрессивной направленности развития морского бассейна. Наибольшую площадь впадина с некомпенсированным осадконакоплением занимала в доманиковое время - на этапе максимальной позднедевонской трансгрессии, которая, вероятно, была вызвана глобальным повышением ОУМ в среднефранское время. В позднефранское время наблюдается последовательное снижение ОУМ, периодически осложнявшееся его повышениями [1].

В соответствии с ранее проведенными палеофациальными исследованиями и результатами сейсмической интерпретации рифовая система позднедевонского возраста в пределах акваториальной части может иметь как субмеридиональное $[1,2]$, так и субширотное простирание.

По результатам выполненного седиментационного моделирования наиболее согласованной по большинству параметров оказалась субширотная система доманиковосирачойских барьерных рифов (рис.2). Полученная фациальная зональность позволила локализовать зоны распространения рифогенных построек, а также более четко оконтурить зону распространения высокопотенциальной доманиковой нефтематеринской толщи. В предрифовой области в пределах впадин обозначились крупные поднятия с дифференцированным рельефом, сводовые части которых, вероятно, являлись «цоколем» одиночных построек различного типа. В районе Поморского вала отложения, ранее интерпретированные как продолжение барьерного рифа $[1,2]$, по результатам проведенных работ, были переквалифицированы на отложения отдельно стоящей карбонатной банки, расположенной в зарифовой области. 


\section{EAGE}

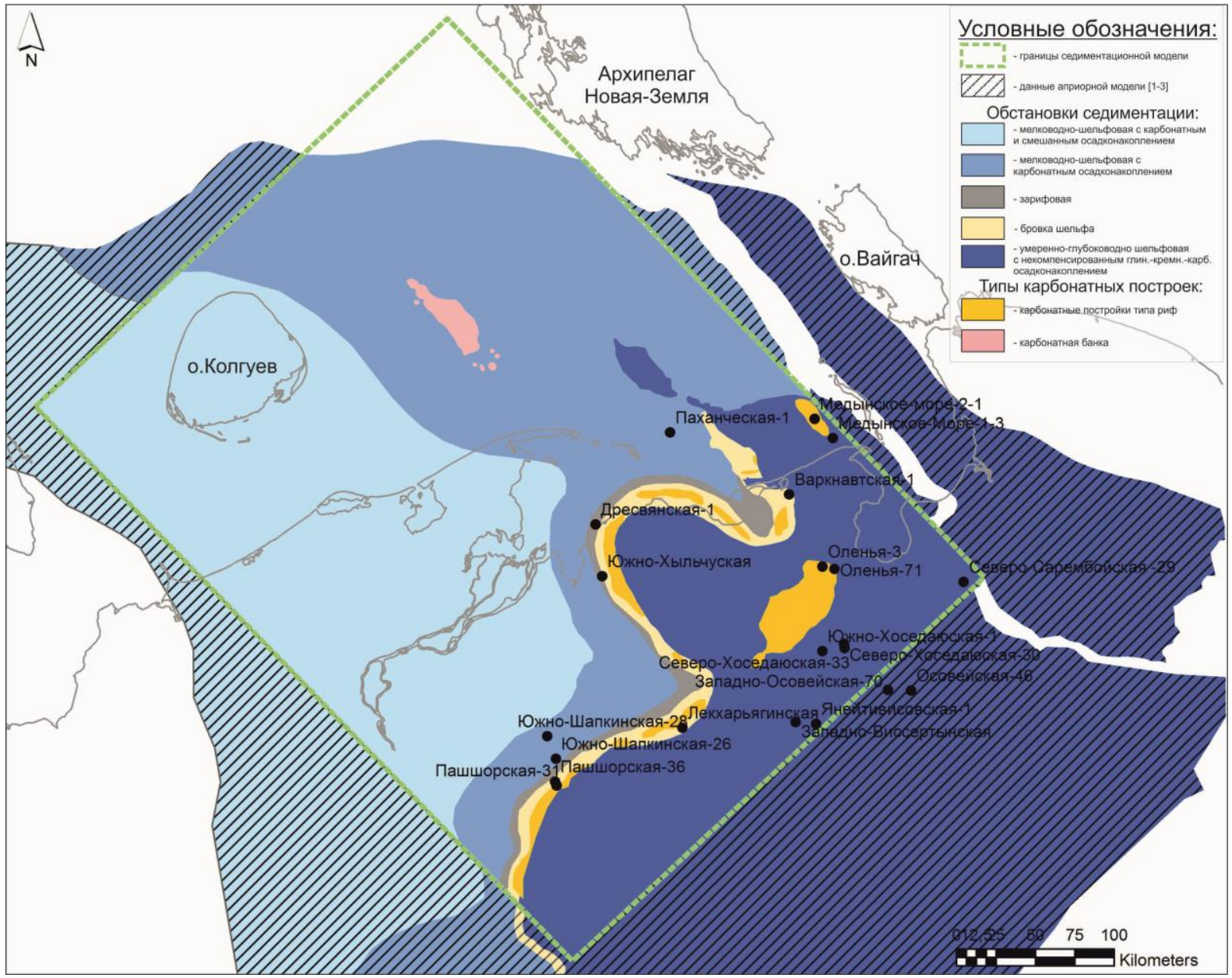

Рисунок 2 Схематическая карта обстановок осадконакопления начала доманикового времени по объединенным априорным [1 - 3] и рассчитанным в модели данным.

Геохимические характеристики доманиковых отложений хорошо коррелируются с фациальной зональностью. Концентрации Сорг (рис.3) изменяются в широком диапазоне (от 0,5 до 10-12\%). Максимальные значения Сорг характерны для кремнисто-глинистых разностей, доломитов и мергелей в пределах Осовейской, Хоседаюсской, Сарембойской и близраположенных площадей. Органическое вещество (OB), как правило, II типа (HI от 300 до 700 мгУВ/гСорг), которое накапливалось в морских обстановках. По качественноколичественным характеристикам изученные отложения доманиковой формации можно отнести к НГМТ, обладающим превосходным генерационным потенциалом.

Отложения доманикового возраста в разрезе скважин Дресвянская-1, Паханческая-1 Медынское-Море-1-3 и Приразломная-5 имеют более низкий потенциал и представлены глинистыми известняками с концентрациями ОВ в среднем 0,7\% (от 0,1 до 2,8\%). Органическое вещество относится к смешанному II-III типу (НI до 160 мгУВ/гСорг). Вероятно, данные отложения накапливались в условиях мелководного шельфа, что подтверждается результатами седиментационного моделирования. 

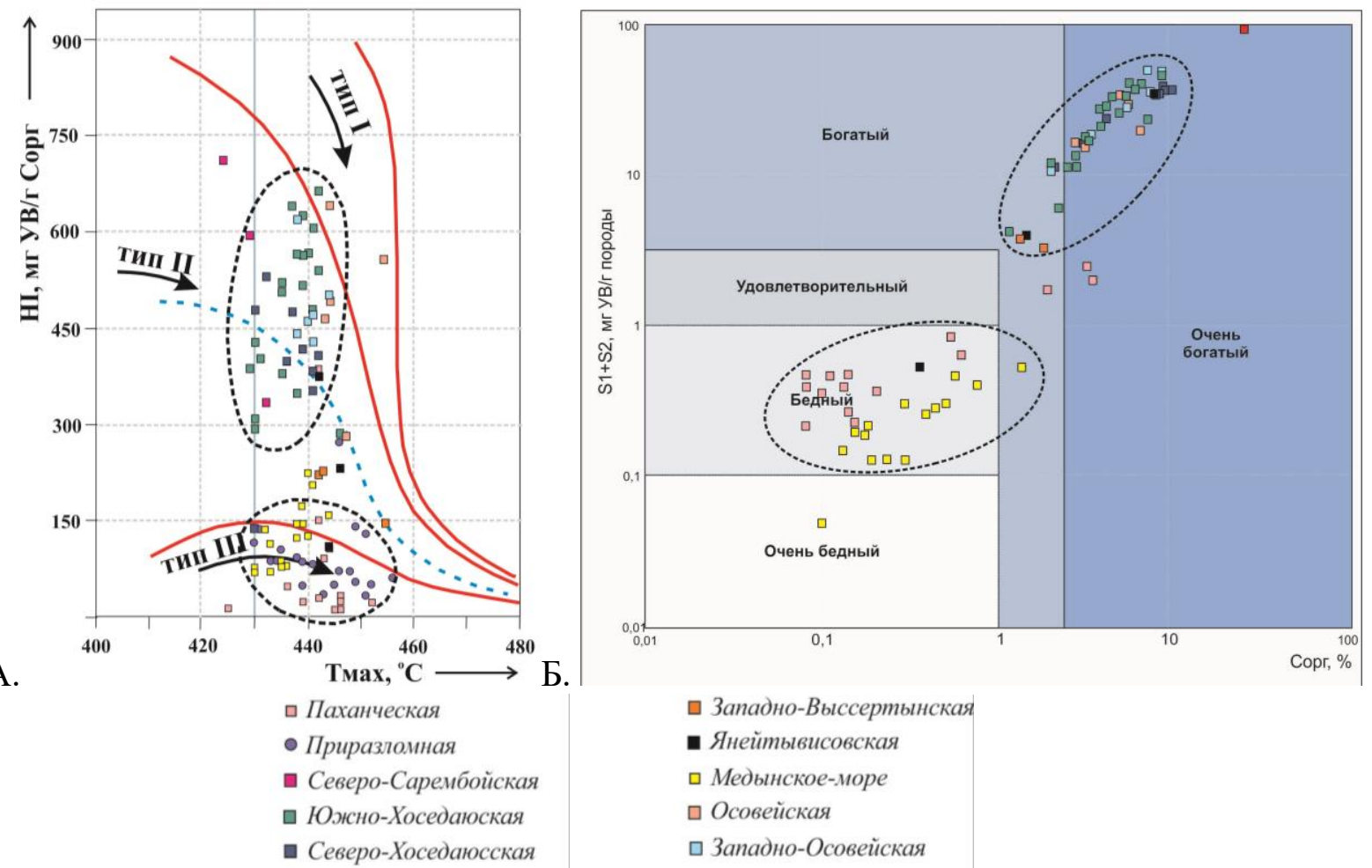

Рисунок 3 Модифицированная диаграмма Ван-Кревелена (A) и график соотношения $S 1+S 2$ и кониентраций Сорг (Б)

Степень катагенетической преобразованности по подошве исследуемых отложений в акваториальном продолжении Печоро-Колвинского авлакогена находится на стадии МК3, постепенно увеличиваясь в северо-восточном направлении (Хорейверская впадина) до МК4АК1. На прилегающей суше исследуемые отложения, в основном, находятся в главной зоне нефтеобразования - значения Ттах изменяются от 424-428 ${ }^{\circ} \mathrm{C}$ (скв. Северо-Сарембойская-19) до $458-461^{\circ} \mathrm{C}$ (скв. Восточно-Ванейвисская-1).

\section{Выводы}

По результатам седиментационного моделирования доманиково-турнейского карбонатного комплекса, с учетом обобщения ранее полученных данных, были выполнены корректировка и детализация палеофациальной реконструкции территории Печорского моря в среднефранское время. Уточненные границы зоны распространения высокопотенциальных НГМТ доманикового горизонта, формировавшихся во впадинах с некомпенсированным осадконакоплением, легли в основу модели генерации и миграции углеводородов. Для потенциальных объектов Печорского моря наиболее вероятной представляется миграция флюидов из Приновоземельской впадины.

\section{Библиография}

1. Жемчугова В.А. Природные резервуары в карбонатных формациях Печорского нефтегазоносного бассейна. - М.: МГГУ, 2002. - 244 с.

2. Никонов Н.И., Богацкий В.И., Мартынов А.В. и др. Атлас геологических карт. ТиманоПечорский седиментационный бассейн. - Ухта, Республика Коми: Региональный Дом печати, 2000. $-67 \mathrm{c}$.

3. Кирюхина Т.А., Большакова М.А., Ступакова А.В. и др. Литолого-геохимическая характеристика доманиковых отложений Тимано-Печорского бассейна // Георесурсы. 2015. - 2(61). - C. 87-100. 


\section{EAGE}

\section{References}

1. Zhemchugova V.A. Reservoirs in carbonate formations of Pechora oil-gas basin. - M.: MGGU, 2002. $-244 \mathrm{p}$.

2. Nikonov N.I And. Bogatsky V.I., Martynov A.V. et al. Atlas of geological maps. The TimanPechora sedimentation basin. - Ukhta, Komi Republic: Regional printing House, 2000. - 67 p.

3. Kiryukhina, T.A., Bolshakova, M.A., Stoupakova A.V. et al. Lithological-geochemical characteristics of domanik formations in the Timan-Pechora basin //Georesources. - 2015. - 2(61). - p. $87-100$ 